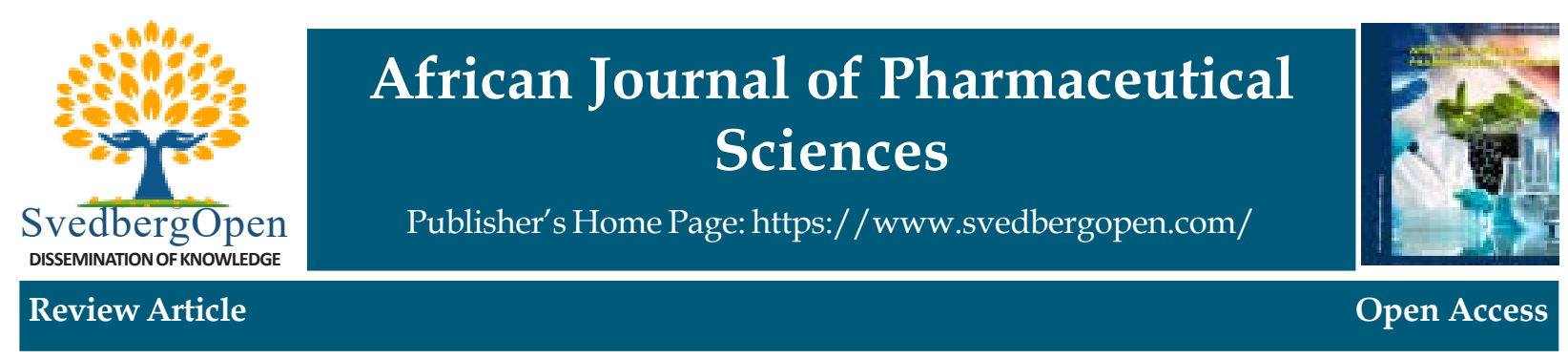

\title{
Survival Strategies of Host, Parasite, and Vector in Human Malaria
}

Fatik Baran Mandal ${ }^{1 *}$

'Department of Zoology, Bankura Christian College, Bankura, West Bengal 722101, India. E-mail: fatikspeaking@yahoo.co.in

Article Info

Volume 1, Issue 1, September 2021

Received : 09 March 2021

Accepted : 12 August 2021

Published : 05 September 2021

doi: 10.51483/AFJPS.1.1.2021.1-10

\begin{abstract}
Malaria, the best example of infectious protozoan diseases, has been tremendously impacted the human genome. The global spread of malaria reflects the successful adaptations of Plasmodium in human host and its Anopheles vector. The potential defenses of Plasmodium deal with diverse mechanisms of host immunity and persist in human with headstrong success. In an evolutionary arms race, human has developed malaria protective polymorphisms to survive. These polymorphisms safeguard human against the malaria. Anopheles has developed pesticide resistance for their survival. This paper briefs the interactions among Plasmodium, Anopheles, and human to provide evolutionary insight on malaria related genetic polymorphisms and to determine the evolutionary fitness of human, Plasmodium and Anopheles.
\end{abstract}

Keywords: Human malaria; Genetic polymorphisms, Insecticide resistance, Drug resistance

(C) 2021 Fatik Baran Mandal. This is an open access article under the CC BY license (https://creativecommons.org/licenses/by/4.0/), which permits unrestricted use, distribution, and reproduction in any medium, provided you give appropriate credit to the original author(s) and the source, provide a link to the Creative Commons license, and indicate if changes were made.

\section{Introduction}

Still now, malaria related human mortality remains high in many countries. In 2018 alone, more than 0.4 million people died due to malaria worldwide, of which more than $90 \%$ in only sub-Saharan Africa (WHO, 2008). Despite our efforts, Plasmodium causes a global health burden of about 250-600 million episodes of malaria per year in Africa, Asia, Latin America, and Oceania (Snow et al., 2005). About $40 \%$ of these episodes are due to P. falciparum, another $40 \%$ is due to P. vivax.

The female Anopheles sucks blood from the host for maturation of their eggs. In the process of sucking blood, they also ingest the male and female gametocytes of Plasmodium, from the infected host. Mature gametocytes of the opposite sexes unite in the mosquito gut to produce the male and female gamete and both the gametes unite to form the rounded zygote. In sporogony, the zygote transforms into the ookinete, which subsequently produces the oocyst that bursts to liberate the sporozoites, the infective stage of Plasmodioum, inhabiting the salivary gland of mosquito. When the infected female Anopheles mosquito sucks blood, the sporozoite takes entry into the blood stream of the human host. Plasmodium undergoes pre-erythrocytic schizogony, erythrocytic schizogony, and gametogony in the human. Asexual life cycle involves RBC and liver cells with ultimate end product of male and female gametocytes in the

* Corresponding author: Fatik Baran Mandal, Department of Zoology, Bankura Christian College, Bankura, West Bengal 722101, India. E-mail: fatikspeaking@yahoo.co.in 
peripheral blood of human from the schizont. In the liver cell, the sporozoite transforms into the schizont, which upon bursting liberates the merozoites, and this cycle in the liver continues and known as the exo-erythrocytic schizogony. Some merozoites enter the RBS and transform into the schizont, which again releases the merozoites. This process of merozoite production in the $\mathrm{RBC}$ is called the erythrocytic schizogony. Some of the merozoites transform into gametocytes in the $\mathrm{RBC}$ through the process called the gametogony. When the mature gametocytes enter the Anopheles during their biting and blood sucking, they develop into the sporozoites in the mosquito. The complexity of malaria is due to factors like presence of confusing sequence of various antigens, which are highly polymorphic in human immune system.

Spread of malaria reflects the successful adaptations of Plasmodium in the human host and its Anopheles vector. The biological success of Plasmodium depends mostly on their capability to invade, grow, and thrive in the human RBCs and liver cells of human. Plasmodium induced behavior in Anopheles also helps the parasite to achieve significant success. Lifecycle stages of Plasmodium impact the host genetic variations, importantly the RBC. Through an evolutionary arms race involving the parasites, hosts and vectors, Plasmodium species have developed survival strategies to effectively deal with the complex immune mechanism of human host and therefore successfully persist in humans.

Historically, the Plasmodium driven selective pressure on the human genome has resulted in the selection of human genetic variants to provide protection against the malaria. Most human diseases of the modern human societies at least partly to be due to malaria driven evolutionary pressure on our ancestors (Kwiatkowski, 2005). Hypoglycemia, glomerulonephritis, and pulmonary edema complicate the malaria (Playfair and Bancroft, 2008). A wealth of published literature deals with malaria protective genetic polymorphism in human (Malaguarnera et al., 2003; López et al., 2010; Lithanatudom et al., 2016; Ravenhall et al., 2018; and Malaria Genomic Epidemiology Network, 2019).

\section{Malaria Protective Human Genetic Polymorphism}

Since some RBC polymorphisms associate with susceptibility, or resistance to malaria, their effects, and distribution would have significant bearing in the epidemiological studies. Environmental condition and ethnicity influence the distribution of polymorphism showing the role played by the environmental natural selection in shaping the human genetic diversity. In the distribution of erythrocytes phenotypes, the ethnic group difference is also important. Interaction between the malaria parasites and human-receptor-ligand mediate the invasion mechanism of the parasite. Interplay between the human host and malaria parasite is balanced to ensure the survival of both, which is evident in the genetics of both the parasite and host (Faik et al., 2009). Human haemoglobinopathies, the first example of balanced polymorphisms protects against malaria and is also associated with the death burden (Roberts and Williams, 2003). There is an association between the host gene mutations and malaria protection. After Haldane's study, Beet (1946) recorded low malaria rates among the sickle-cell carriers than among the non-sicklers. However, presently consensus on how haemoglobinopathies bestow malaria protection appears to be lacking. Different haemoglobinopathies cause decreased growth and virulence of Plasmodium, mild haemolytic condition, auto-oxidation of haemoglobin, and ineffective erythropoiesis (Genton et al., 1995; and Roberts and Williams, 2003). However, perhaps the same mechanism does not operate in such cases. Plasmodium spp. have co-evolved together with human for thousands of years (Jongwutiwes et al., 2005).

\section{Plasmodium Vivax Offers Protection to Human}

Zimmerman et al. (2013) stated that for the P. vivax the human Duffy antigen on RBCs is the receptor of parasites. Absence of such receptor due to fy gene mutations prevents the entry of Plasmodium into the RBCs and protects the human against vivax malaria (Zimmerman et al., 1999). Combined missense mutation and lack of glycoprotein receptors on RBCs enhances the P. vivax resistance (Pogo and Chaudhuri, 2000). Two chief polymorphisms are found in fy gene. The Asp $\rightarrow$ Gly peptides replacement associates with the Fyb and Fya blood group antigens, corresponding with the first polymorphism. The second polymorphism leads to negative Duffy expression by silent RBCs (Murphy et al., 2000). Individuals with the Fya are more resistant to $P$. vivax infections. In Haiti, $99 \%$ of patients having silent erythrocytes with no Duffy antigen expression was P. vivax negative (Weppelmann et al., 2013). G6PD deficiency protects against the P. vivax infections and protects both the hemizygous males and heterozygous females from severe malaria (Clark et al, 2009); also protective against severe malaria and limits the severe anemia imposed increased risk (Shah et al., 2016).

Glycophorins (GYPA, GYPB, and GYPC) attach with the surface membrane proteins of Plasmodium (Wassmer and Carlton, 2016) and play role in bringing out the clinical malaria. Consequently, in absence of glycophorin, the entry of parasite in RBCs reduces and thus provides protection against the malaria (Maier et al., 2003). Dantu mutation in glycophorin molecules draws special attention. Through a specific impact on receptor-ligand interaction Dantu reduces 
invasion but rather through a more non-specific way whereby Dantu increases red cell tension (Kariukki et al., 2018). Glucose-6-phosphate dehydrogenase (G6PD) is linked to protection against the P. vivax, but not against the P. falciparum malaria (Louicharoen et al., 2009). In the western Africa, P. vivax is not very common because most of the population is Duffy negative (Chitnis and Miller, 1994).

\section{Resistance against Plasmodium falciparum in Human}

In people with erythropoietic protoporphyria, the RBCs become unsuitable for $P$. falciparum due to low level of ferrochelatase in such patient with resistance to P. falciparum (Smith et al., 2015). CD36 receptor binds with the vascular endothelial cells, activated immune cell surfaces, and play role in lipid metabolism as well as in phagocytosis. CD36 deficiency derived reduced cytoadherence of the infected RBCs protects the children against the anemia (Chingola et al., 2009; and Ochola et al., 2011). The host gene APOBEC3B mediates the innate response in P. falciparum infection. Enhanced frequency of deleted allele shows correlation with the higher susceptibility to P. falciparum (Jha et al., 2012). Malaria thus serves as a positive selection force for APOBEC3B insertion. The mutants--MBL2 and MASP2 affect the congenital malaria as well as the placental transmission (Holmberg et al., 2012). In Africa, double mutations in MBL gene in children with severe malignant malaria occur naturally (Luty et al., 1998).

The severity of infection, and cerebral complications in falciparum malaria (Fernandez-Reyes et al., 1997) increases mutation in gene encoding adhesion molecule 1 (ICAM-1, CD54). Malignant malaria has linkage with polymorphisms, MBL gene, promoter regions of the tumor necrosis factor- $\alpha$ (TNF- $\alpha$ ) and nitric oxide synthesis 2 (NOS2). Point mutation in NOS2 produces the higher NO and protect against the $P$. falciparum malaria (Coia et al., 2005). The MBL gene mutation and severe manifestations of P. falciparum is correlated in children from the Ghana (Holmberg et al., 2008). A mutation in gene coding TNF- $\alpha$ was identified as a risk factor for P. falciparum re-infections (Meyer et al., 2002). The anion-exchange protein prevents the binding of infected RBCs with endothelial cells (von Kalckreeuth et al., 2006). Children with mutation in gene encoding anion-exchange protein 1 face severe malignant malaria.

Plasmodium has significant impact on human evolution (Cavalli-Sfroza et al., 1994). To escape, the host immunity Plasmodium sequesters in the deep capillaries (Rowe et al., 1995; Williams et al., 2002; and Rowe et al., 2009). Haldane (1948) first proposed the "malaria hypothesis." Allison et al. (1954) thought that selection through malaria might explain the high frequency of $\mathrm{HbS}$ in malaria endemic areas which confers the strongest protection against the severe malaria with more than $80 \%$ in heterozygous carriers (HbAS ; sickle cell trait). In the Alpha thalassaemia patient, about $40 \%$ homozygotes remains malaria protected (MGEN, 2014; and Ndila et al., 2018). In malaria endemic region, other protective RBC polymorphisms including the glucose-6-phosphatase (G6PD) deficiency, O blood group, and gene variants for complement receptor 1 (CR1) occur at varied frequencies (Kwiatkowski, 2005). Duffy Antigen Receptor for Chemokines (DARC), which is expressed on RBC membranes exert strong selective pressure on the human genome and serve both as a chemokine receptor (Pogo and Chaudhuri, 1995) and a receptor for merozoites of Plasmodium vivax (Chitnis and Miller, 1994).

\section{Malaria Protective Genes}

The heparan sulfate proteoglycans of the human attaches with the circumsporozoite protein (a protein of parasite) of Plasmodium. The host genes viz. HS3ST3A1 and HS3ST3B1 encode for the enzymes, required for synthesis of heparan sulfate proteoglycans that probably influence malaria (Atkinnson et al., 2012). Mutation of Fc $\gamma$ RIIa (CD32 gene) affects the affinity of receptor for human IgG. Malaria resistance is associated with the gene that encodes for chitotriosidase (Chit). Chit gene mutation in higher frequency in Mediterranean population relates with high malaria resistance (Kanneegati et al., 2012). Mutant hemoglobin variants like sickle-cell anemia (Ayi et al., 2004) or thalassemia (Mokenhaupt et al., 2004) provide significant protection against the human malaria. More than 180 mutations are associated with the PK deficiency (Min-Oo et al., 2003).

The liver/erythrocyte specific enzyme (PKLR) contributes for energy generation for mature RBCs. Deficiency of PKLR causes the nonspherocytic hemolytic anemia, which inherits as an autosomal recessive. RBCs of PKLRdeficient patients reduce parasite's entry in RBCs and enhance the early phagocytosis of infected RBCs (Durand and Coetzer, 2008). The partial or complete loss of PKLR function results in malaria protection (van Buuggen et al., 2015).

The ANK-1 gene encodes the Ankyrin-1, a cytoskeletal protein on the RBC membrane and its mutation mediates the human-inherited hemolytic anemic disorders. t ank-1 mutation enhances the malaria resistance (Greth et al., 2012). Mild 
malaria is found in boys with hemoglobin AA and O blood group. Similarly, the girls without mutation in gene encoding G6PD exhibits the mild malaria (Migot-Nabias et al., 2000). Mutation related only to TNF- $\alpha$ has an association with the serious manifestations. However, nor the promoter regions of neither NOS2 nor the MBL gene are involved with the malaria manifestations (Migot Nabias et al., 2000). Protection in Indian patients from clinical malaria was also found (Dhangadamajhi et al., 2009).

\section{Insecticide Resistance}

Extensive use of DDT and pyrethroids increase the KDR mutation rate resulting in emergence of new mutation to ACE1R (organophosphates) in An. gambiae (Cooling, 2015; and Tizifa et al., 2018). Both the mutations influence (KDR and ACE-1R) the outcome of malaria transmission (Leucet et al., 2012). The KDR resistant strain reduces the parasite burden, compared with the susceptible strain (Reimer et al., 2016). Such reduction has not been observed in ACE-1R mutation. This gives us warning against the extensive use of DDT and pyrethroid (Alout et al., 2013). Deletion of gene mutation at KDR locus increases the susceptibility of An. gambiae to P. falciparum infection. Development of new strategy for malaria control should consider all these evolution driven results (Ndiath et al., 2014). KDR mutations are found in 13 Anopheles species. Insecticide resistance programs in malaria endemic regions should carry out, and monitored routinely (Silva et al., 2014). The increased frequency of KDR mutations in An. funestus in Mali (Riveron et al., 2015) and An. arabiensis in Senegal (Ndiath et al., 2015) are also documented.

\section{Drug Resistance}

Chloroquine was effective, cheap, and easy to use in Africa and it was supplied in massive quantities. As a result, children death due to malaria in Africa was dropped in 1970s related in approaching half the level of pre-chloroquine years (Carter and Mendis, 2002). In the late 1970s, chloroquine-resistant falciparum took entry into the Africa and began to spread rapidly. Consequently, the malaria related morbidity and mortality resurged (Trape et al., 1998). Mortality due to the malaria across large areas again approached the levels of pre-chloroquine years in the late 1990s. The former efficacy of chloroquine against the falciparum malaria produced major global health impacts of any ever-discovered antimicrobial drug. Spread of resistant parasites caused treatment failures and showed clearly how easily a drug can become ineffective in the therapy-based combinations in many African countries. Cytochrome P450 is involved in the artemisinin metabolism. Based on the frequency distribution (ranges between 10\% and 78\%) of cytochrome P450 mutation variants in Tanzanian falciparum patients, further evaluation of drug for the treatment of malignant malaria was suggested in Tanzania (Marwa et al., 2014).

Frequency distribution of 62 mutations, the main cause of evolution locates on 17 human chromosomes (candidate immune genes). Study assessed the genes encoding immune response factors involved in the clearance of drug resistant mutant parasites in Cameroonian children. CD36, TNF- $\alpha$, IL-22, IL-4, IL-10, and IL-17 are vital for clearance of resistant parasites (Ali et al., 2011; Vincent and N"Guessan, 2013; Menze et al., 2016; and Ondento et al., 2017).

\section{Fitness of Plasmodium}

Now, it is clear that the human-Plasmodium interactions have resulted in malaria protective genetic polymorphisms through mediation of various genes in human and drug resistance in Plasmodium, which leads to the greater longevity of Plasmodium in human, and consequently extends the period of infectiveness. Gene mutation and selection of resistant mutants produce drug and insecticide resistance (Beagle, 1980). Chloroquine-resistant $P$. falciparum are prevalent throughout the world except Haiti, North Africa, Mexico, the Dominican Republic, and Central America. Mefloquine resistance is found in South-east Asia, especially in parts of the Africa and South America, Thailand, the Middle East, and Oceania. Quinine resistance is also common in the South Asia, Brazil and parts of Africa. Sulfadoxine/ pyrimethamine resistance has recorded in the Indian subcontinent, South-east Asia, the Amazon basin, Oceania (Reviewed in Kristian et al., 2003).

In the history of life, the lifestyle of parasite was incredibly successful. A fitness consequence of human malaria parasite rhythm is advantageous for parasites to have a definite phase relative to rhythm of the host. Hawking hypothesis has been reviewed for success of human malaria parasites (reviewed in Reece et al., 2017). This hypothesis states that parasites change or match their behaviors to maximize opportunities to transmit the parasites to a vector. While discussing the parasite offense and host defense (Reece et al., 2017) noted the induction of a strong inflammatory response due to synchronized bursting of Plasmodium in blood stream causing immunopathology of the host. Such 
bursting benefits the parasite for its multiplication facility but harm the human health. Recently researchers have shown that people with transmittable malaria attracts mosquito. Sweat and breath odor in addition to high body temperature, enhances mosquito's lust for human blood (Lacroix et al., 2005). Hamilton realized that in case of increasingly less random mating, the natural selection favors skewed sex ratios strongly towards the females, to reduce wastage of resources on males that compete with each other for the same fertilization. Life cycles that favor this type of sex allocation behavior are widespread. Life cycle of Plasmodium selects for the evolution of 'Hamiltonian' sex ratio behavior. Key assumptions and predictions of sex allocation theory are upheld in malaria parasites, which help us to better understand the biology and within-host behavior of the malaria parasites (reviewed in Knowles and Sheldon, 2008).

Now the contribution of various fitness components to the overall fitness of sensitive and resistant Plasmodium are (i) growth and decay rates of the merozoites under drug pressure; (ii) starting of the gametocytogenesis; (iii) duration of gametocytes in blood stream; (iv) threshold gametocytaemia for transmissibility; (v) isolation periods of clinical malaria episodes. The gametocytes occur earlier in P. vivax but persist longer in P. falciparum. Late gametocytogenesis in infection and longer lifespan of the gametocytes will promote the spread of drug resistance. Thus, when comparing these two malarial parasites, resistance will spread easier in P. falciparum than in P. vivax. Transmission is the ultimate measure of the parasites' fitness (Reviewed in Schneider and Escalante, 2013). Although malaria protective genetic polymorphisms provide protection against the malaria, it definitely reduces fitness of human host because of vast burden of haemoglobinopathies.

Lastly, it is safe to conclude that history of malaria for at least last six thousand years is on record although definitely not systematically, which shows that Plasmodium offers cost in the form of mutation, manipulating the host and vector behavior for its successful spread and to ensure its survival. Human hosts have also helped Plasmodium in extending their cellular niche through human population expansion, drastic changes in the environment, and by promoting the unscientific use of insecticides. Plasmodium falciparum is virulent and life threatening. Other malaria parasite is benign, less virulent and all these factors increases their fitness or the evolutionary success.

\section{Conclusion}

Ultimate aim of survival is the production of copies of genes through reproduction (Mandal, 2015). Transmission efficiency, manipulation with the host and parasite behaviors, less virulence, not to threaten the survival of hosts and vectors are undoubtedly the fitness component of Plasmodium. Now, it appears that $P$. falciparum is less fit than the P. vivax. It would be of great interest to predict the success of new Anopheles-Plasmodium interactions in the context of drastic environmental changes such as global warming. The outcome of infection is the parasite genotype-vector genotype dependent; no parasite has optimal transmission in all the hosts and no host resists all the parasites. An. gambiae can be highly susceptible to some parasite genotypes, and, at the same time, highly resistant to other (Lambrechts et al., 2005). That mutations provide the protection to human against the malaria are highly prevalent in malaria endemic regions (Yuthavong and Wilairat,1993). As per Haldane's malaria hypothesis (Haldane, 1949), this might result in a "balanced polymorphism". In such conditions, the homozygote's hematological disadvantage balances the malaria resistance, which heterozygote exhibits (Yuthavong and Wilairat,1993). Malaria protective polymorphisms exhibit varied geographical distribution, parasite growth inhibition ability, and increased ability for host phagocytosis (Roberts and Williams, 2003). Genetically based resistance mechanism perhaps determine the geographic distribution of the parasites in both severe and non-severe cases of malaria and in homozygotic, or heterozygotic individuals (Hill et al., 1991; Lelliott et al., 2015; and Howes et al., 2016). Plasmodium-human co evolution confers protection against the malaria to the host and, it also limits the virulence of parasite allowing it to remain within the host for a longer period of time (Leung et al., 2017). Insecticide resistances of the Anopheles vector certainly shape the parasite-vector dynamics.

\section{References}

Ali, A.A.A., Elhassan, E.M., Magzoub, M.M., Elbashir, M.I., and Adam, I. (2011). Hypoglycaemia and Severe Plasmodium falciparum Malaria among Pregnant Sudanese Women in an Area Characterized by Unstable Malaria Transmission. Parasites and Vectors, 4(1), 88. doi:10.1186/1756-3305-4-88, PubMed: 21605445.

Allison, A.C. (1954). Protection Afforded by Sickle-Cell Trait against Sub Tertian Malarial Infection. British Medical Journal, 1(4857), 290-294. doi:10.1136/bmj.1.4857.290, PubMed: 13115700. 
Alout, H., Ndam, N.T., Sandeu, M.M., Djégbe, I., Chandre, F., Dabiré, R.K. et al. (2013). Insecticide Resistance Alleles Affect Vector Competence of Anopheles Gambiaes. PLOS ONE, 8(5), e63849. doi:10.1371/journal.pone.0063849, PubMed: 23704944.

Atkinson, J.A., Johnson, M.L., Wijesinghe, R., Bobogare, A., Losi, L., O’Sullivan, M., Yamaguchi, Y., Kenilorea, G., Vallely, A., Cheng, Q., Ebringer, A., Bain, L., Gray, K., Harris, I., Whittaker, M., Reid, H., Clements, A., Shanks, D. (2012). Operational Research to Inform a Sub-national Surveillance Intervention for Malaria Elimination in Solomon Islands. Malar J., 11:101. doi: 10.1186/1475-2875-11-101. PMID: 22462770; PMCID: PMC3359162.

Ayi, K., Turrini, F., Piga, A., and Arese, P. (2004). Enhanced Phagocytosis of Ring Parasitized Mutant Erythrocytes: A Common Mechanism that May Explain Protection against Falciparum Malaria in Sickle Trait and Beta-Thalassemia Trait. Blood., 104(10): 3364-71. doi: 10.1182/blood-2003-11-3820. Epub 2004 Jul 27. PMID: 15280204.

Beale, G.H. (1980). The Genetics of Drug Resistance in Malaria Parasites. Bulletin of the World Health Organization, 58(5), 799-804. PubMed: 7028302.

Beet, E.A. (1946). Sickle Cell Disease in the Balovale District of Northern Rhodesia. East African Medical Journal, 23 , 75-86. PubMed: 21027890.

Carter, R., and Mendis, K.N. (2002). Evolutionary and Historical Aspects of the Burden of Malaria. Clinical Microbiology Reviews, 15(4), 564-594. doi:10.1128/cmr.15.4.564-594.2002, PubMed: 12364370.

Cavalli-Sforza, L.L. et al. (1994). The History and Geography of Human Genes. Princeton: Princeton University Press.

Chilongola, J., Balthazary, S., Mpina, M., Mhando, M., and Mbugi, E. (2009). CD36 Deficiency Protects against Malarial Anemia in Children by Reducing Plasmodium falciparum-Infected Red Blood Cell Adherence to Vascular Endothelium. Tropical Medicine and International Health, 14(7), 810-816. doi:10.1111/j.1365-3156.2009.02298.x, PubMed: 19413744.

Chitnis, C.E., and Miller, L.H. (1994). Identification of the Erythrocyte Binding Domains of Plasmodium vivax and Plasmodium knowlesi Proteins Involved in Erythrocyte Invasion. Journal of Experimental Medicine, 180(2), 497506. doi:10.1084/jem.180.2.497, PubMed: 8046329.

Clark, T.G.G., Fry, A.E., Auburn, S., Campino, S., Diakite, M., Green, A., et al. (2009). Allelic Heterogeneity of G6PD Deficiency in West Africa and Severe Malaria Susceptibility. European Journal of Human Genetics, 17(8), 1080 1085. doi:10.1038/ejhg.2009.8, PubMed: 19223928.

Coia, V., Jüliger, S., Mordmüller, B., Kreidenweis, A., Stroh, A. L., Ortega, C., et al. (2005). Analysis of Polymorphic Sites in the Promoter of the Nitric Oxide Synthase 2 Gene. Biochemical and Biophysical Research Communications, 335(4), 1123-1131. doi:10.1016/j.bbrc.2005.07.178, PubMed: 16105645.

Cooling, L. (2015). Blood Groups in Infection and Host Susceptibility. Clinical Microbiology Reviews, 28(3), 801-870. doi:10.1128/CMR.00109-14, PubMed: 26085552.

Dhangadamajhi, G., Mohapatra, B.N., Kar, S.K., and Ranjit, M. (2009). Endothelial Nitric Oxide Synthase Gene Polymorphisms and Plasmodium falciparum Infection in Indian Adults. Infection and Immunity, 77(7), 2943-2947. doi:10.1128/IAI.00083-09, PubMed: 19364839.

Durand, P.M.M. and Coetzer, T.L. (2008). Pyruvate Kinase Deficiency Protects against Malaria in Humans. Haematologica, 93(6), 939-940. doi:10.3324/haematol.12450, PubMed: 18460648.

Faik, I., de Carvalho, E.G. and Kun, J.F. (2009). Parasite-Host Interaction in Malaria: Genetic Clues and Copy Number Variation. Genome Medicine, 1(9), 82. doi:10.1186/gm82, PubMed: 19725943.

Fernandez-Reyes, D., Craig, A.G., Kyes, S.A., Peshu, N., Snow, R.W., Berendt, A.R., et al. (1997). A High Frequency African Coding Polymorphism in the N-terminal Domain of ICAM-1 Predisposing to Cerebral Malaria in Kenya. Human Molecular Genetics, 6(8), 1357-1360. doi:10.1093/hmg/6.8.1357, PubMed: 9259284.

Genton, B., al-Yaman, F., Mgone, C.S., Alexander, N., Paniu, M.M., Alpers, M.P., and Mokela, D. (1995). Ovalocytosis and Cerebral Malaria. Nature, 378(6557), 564-565. doi:10.1038/378564a0, PubMed: 8524388. 
Greth, A., Lampkin, S., Mayura-Guru, P., Rodda, F., Drysdale, K., Roberts Thomson, M., et al. (2012). A Novel ENUMutation in Ankyrin-1 Disrupts Malaria Parasite Maturation in Red Blood Cells of Mice. PLOS ONE, 7(6), e38999. doi:10.1371/journal.pone.0038999, PubMed: 22723917.

Haldane, J.B.S. (1948). The Rate of Mutation of Human Genes. Hereditas, 35(S1) (Suppl. 1) [Suppl., 267-273], $267-273$. doi:10.1111/j.1601-5223.1949.tb03339.x.

Haldane, J.B.S. (1949). Disease and Evolution. Ricerca Scientifica Suppl., 19, 3-10, Hamblin MT.

Hill, A.V., Allsopp, C.E., Kwiatkowski, D., Anstey, N.M., Twumasi, P., Rowe, P.A., et al. (1991). Common West African HLAAntigens are Associated with Protection from Severe Malaria. Nature, 352(6336), 595-600. doi:10.1038/352595a0, PubMed: 1865923.

Holmberg, V., Onkamo, P., Lahtela, E., Lahermo, P., Bedu-Addo, G., Mockenhaupt, F.P., and Meri, S. (2012). Mutations of Complement Lectin Pathway Genes MBL2 and MASP2 Associated with Placental Malaria. Malaria Journal, 11, 61. doi:10.1186/1475-2875-11-61, PubMed: 22380611.

Holmberg, V., Schuster, F., Dietz, E., Sagarriga Visconti, J.C., Anemana, S.D., Bienzle, U., and Mockenhaupt, F.P. (2008). Mannose-Binding Lectin Variant Associated with Severe Malaria in Young African Children. Microbes and Infection, 10(4),342-348. doi:10.1016/j.micinf.2007.12.008, PubMed: 18396436.

Howes, R.E.E. et al. (2016). Contemporary Epidemiological Overview of Malaria in Madagascar: Operational Utility of Reported Routine Case Data for Malaria Control Planning. Malaria Journal, 15(1), 502. doi:10.1186/s12936-0161556-3http://dx.doi.org/10.5772/56117. PubMed: 27756389.

Jha, P., Sinha, S., Kanchan, K., Qidwai, T., Narang, A., Singh, P.K., et al. (2012). Deletion of the APOBEC3B Gene Strongly Impacts Susceptibility to Falciparum Malaria. Infection, Genetics and Evolution, 12(1), 142-148. doi:10.1016/ j.meegid.2011.11.001, PubMed: 22108670.

Jongwutiwes, S., Putaporntip, C., Iwasaki, T., Ferreira, M.U., Kanbara, H., and Hughes, A.L. (2005). Mitochondrial Genome Sequences Support Ancient Population Expansion in Plasmodium vivax. Molecular Biology and Evolution, 22(8), 1733-1739. doi:10.1093/molbev/msi168, PubMed: 15901839.

Kanneganti, M., Kamba, A., and Mizoguchi, E. (2012). Role of Chitotriosidase (Chitinase 1) Under Normal and Disease Conditions. Journal of Epithelial Biology and Pharmacology, 5, 1-9. doi:10.2174/1875044301205010001, PubMed: 23439988 .

Kariuki, S. N., Marin-Menendez, A., Introini, V. et al. (2018). Red Blood Cell Tension Controls Plasmodium falciparum Invasion and Protects against Severe Malaria in the Dantu Blood Group. bioRxiv.https ://doi. doi:10.1101/475442.

Knowles, S.C., and Sheldon, B.C. (2008). Evolutionary Biology: Parasite, Know Thyself. Current Biology, 18(15), R655R657. doi:10.1016/j.cub.2008.06.032, PubMed: 18682205.

Kristian, H., and Pramila Vivek, H.V.H. (2003). The Behavioural and Social Aspects of Malaria and its Control an Introduction and Annotated Bibliography 2003UNDP/World Bank/WHO Special Programme for Research and Training in Tropical Diseases (TDR) UNDP/World Bank/WHO.

Kwiatkowski, D.P. (2005). How Malaria has Affected the Human Genome and What Human Genetics Can Teach us about Malaria. American Journal of Human Genetics, 77(2), 171-192. doi:10.1086/432519, PubMed: 16001361.

Lacroix, R., Mukabana, W.R., Gouagna, L.C., Koella, J.C., Louis Clement Gouagna., and Jacob C. (2005). Malaria Infection Increases Attractiveness of Humans to Mosquitoes. PLOS Biology, 3(9), e298. doi:10.1371/journal.pbio.0030298.

Lambrechts, L., Halbert, J., Durand, P., Gouagna, L.C., and Koella, J.C. (Hosts). (2005). Host Genotype by Parasite Genotype Interactions Underlying the Resistance of Anopheline Mosquitoes to Plasmodium falciparum. Malaria Journal, 4, 3. doi:10.1186/1475-2875-4-3.

Lelliott, P.M.M., McMorran, B J., Foote, S.J., and Burgio, G. (2015). The Influence of Host Genetics on Erythrocytes and Malaria Infection: Is there Therapeutic Potential? Malaria Journal, 14, 289. doi:10.1186/s12936-015-0809-x, PubMed: 26215182.

Leung, J.M.M., Fishbane, N., Jones, M., Morin, A., Xu, S., Liu, J. C., et al. (2017). Longitudinal Study of Surrogate aging Measures During Human Immunodeficiency Virus Seroconversion. Aging, 9(3), 687-705. doi:10.18632/aging.101184, PubMed: 28237978. 
Lithanatudom, P., Wipasa, J., Inti, P., Chawansuntati, K., Svasti, S., Fucharoen, S., et al. (2016). Hemoglobin E Prevalence among Ethnic Groups Residing in Malaria-Endemic Areas of Northern Thailand and its Lack of Association with Plasmodium falciparum Invasion in Vitro. PLOS ONE, 11(1), e0148079. doi:10.1371/journal.pone.0148079, PubMed: 26808200.

López, C., Saravia, C., Gomez, A., Hoebeke, J., and Patarroyo, M. A. (2010). Mechanisms of Genetically-Based Resistance to Malaria. Gene, 467(1-2), 1-12. doi:10.1016/j.gene.2010.07.008, PubMed: 20655368.

Louicharoen, C., Patin, E., Paul, R., Nuchprayoon, I., Witoonpanich, B., Peerapittayamongkol, C., et al. (2009). Positively Selected G6PD-Mahidol Mutation Reduces Plasmodium vivax Density in Southeast Asians. Science, 326(5959), 1546-1549. doi:10.1126/science.1178849, PubMed: 20007901.

Lucet, I.S., Tobin, A., Drewry, D., Wilks, A.F., and Doerig, C. (2012). Plasmodium kinases as Targets for New-Generation Antimalarials. Future Medicinal Chemistry, 4(18), 2295-2310. doi:10.4155/fmc.12.183, PubMed: 23234552.

Luty, A.J., Kun, J.F., and Kremsner, P.G. (1998). Mannose-Binding Lectin Plasma Levels and Gene Polymorphisms in Plasmodium falciparum Malaria. Journal of Infectious Diseases, 178(4), 1221-1224. doi:10.1086/515690, PubMed: 9806066.

Maier, A.G.G., Duraisingh, M.T., Reeder, J.C., Patel, S.S., Kazura, J.W., Zimmerman, P.A., and Cowman, A.F. (2003). Plasmodium falciparum Erythrocyte Invasion Through Glycophorin C and Selection for Gerbich Negativity in Human Populations. Nature Medicine, 9(1), 87-92. doi:10.1038/nm807, PubMed: 12469115.

Malaguarnera, L., Simporè, J., Prodi, D.A., Angius, A., Sassu, A., Persico, I., et al. (2003). A 24-bp Duplication in Exon 10 of Human Chitotriosidase Gene from the Sub-Saharan to the Mediterranean Area: Role of Parasitic Diseases and Environmental Conditions. Genes and Immunity, 4(8), 570-574. doi:10.1038/sj.gene.6364025, PubMed: 14647197.

Malaria Genomic Epidemiology Network and Malaria Genomic Epidemiology Network. (2014). Reappraisal of Known Malaria Resistance Loci in a Large Multicenter Study. Nature Genetics, 46(11), 1197-1204. doi:10.1038/ng.3107, PubMed: 25261933.

Malaria Genomic Epidemiology Network. (2019). Insights into Malaria Susceptibility Using Genome-Wide Data on 17,000 Individuals from Africa, Asia and Oceania. Nature Communications, 10(1), 5732. doi:10.1038/s41467-01913480-z, PubMed: 31844061.

Mandal, F.B. (2015). Textbook of Animal Behaviour. PHI Learning Pvt Ltd. New Delhi.

Marwa, K.J.J., Schmidt, T., Sjögren, M., Minzi, O.M., Kamugisha, E., and Swedberg, G. (2014). Cytochrome P450 Single Nucleotide Polymorphisms in an Indigenous Tanzanian Population: A Concern about the Metabolism of ArtemisininBased Combinations. Malaria Journal, 13, 420. doi:10.1186/1475-2875-13-420, PubMed: 25363545.

Menze, B.D., Riveron, J.M., Ibrahim, S. S., Irving, H., Antonio-Nkondjio, C., Awono-Ambene, P.H., and Wondji, C.S. (2016). Multiple Insecticide Resistance in the Malaria Vector Anopheles Funestus from Northern Cameroon is Mediated by Metabolic Resistance Alongside Potential Target Site Insensitivity Mutations. PLOS ONE, 11(10, October 10), e0163261. doi:10.1371/journal.pone.0163261, PubMed: 27723825.

Meyer, C.G., May, J., Luty, A.J., Lell, B., and Kremsner, P.G. (2002). TNFalpha 308AAssociated with Shorter Intervals of Plasmodium falciparum Reinfections. Tissue Antigens, 59(4), 287-292. doi:10.1034/j.1399-0039.2002.590406.x, PubMed: 12135427.

Migot-Nabias, F., Mombo, L.E., Luty, A.J., Dubois, B., Nabias, R., Bisseye, C., et al. (2000). Human Genetic Factors Related to Susceptibility to Mild Malaria in Gabon. Genes and Immunity, 1(7), 435-441. doi:10.1038/sj.gene.6363703, PubMed: 11196674.

Min-Oo, G., Fortin, A., Tam, M.F., Nantel, A., Stevenson, M.M., and Gros, P. (2003). Pyruvate Kinase Deficiency in Mice Protects against Malaria. Nature Genetics, 35(4), 357-362. doi:10.1038/ng1260, PubMed: 14595440.

Mockenhaupt, F.P.P., Ehrhardt, S., Gellert, S., Otchwemah, R.N., Dietz, E., Anemana, S.D., and Bienzle, U. (2004). Alpha (+)-thalassemia Protects African Children from Severe Malaria. Blood, 104(7), 2003-2006. doi:10.1182/blood 200311-4090, PubMed: 15198952. 
Murphy, P.M., Baggiolini, M., Charo, I.F., Hébert, C.A., Horuk, R., Matsushima, K., et al. (2000). International Union of Pharmacology. XXII Nomenclature for Chemokine Receptors. Pharmacological Reviews, 52(1), 145-176. PubMed: 10699158.

Ndiath, M.O., Cailleau, A., Diedhiou, S.M., Gaye, A., Boudin, C., Richard, V. and Trape, J.F. (2014). Effects of the Kdr Resistance Mutation on the Susceptibility of Wild Anopheles Gambiae Populations to Plasmodium falciparum: A Hindrance for Vector Control. Malaria Journal, 13, 340. doi:10.1186/1475-2875-13-340, PubMed: 25176292.

Ndiath, M.O., Cailleau, A., Orlandi-Pradines, E., Bessell, P., Pagès, F., Trape, J.F., Rogier, C., Orlandi-Pradines E. et al. (2015). Emerging Knock-Down Resistance in Anopheles Arabiensis Populations of Dakar, Senegal: First Evidence of a High Prevalence of kdr-e Mutation in West African Urban Area. Malaria Journal, 14, 364. doi:10.1186/s12936015-0898-6, PubMed: 26395241

Ndila, C.M., Uyoga, S., Macharia, A.W. et al. (2018). Human Candidate Gene Polymorphisms and Risk of Severe Malaria in Children in Kilifi, Kenya: A Case Control Association Study. Lancet Haematol. https ://doi. doi:10.1016/s23523026(18)30107-8.

Ochola, L.B.B. et al. (2011). Specific Receptor Usage in Plasmodium falciparum Cytoadherence is Associated with Disease Outcome. PLOS ONE, 6(3), e14741. Published. doi:10.1371/journal.pone.0014741, PubMed: 21390226.

Ondeto, B.M., Nyundo, C., Kamau, L., Muriu, S.M., Mwangangi, J.M., Njagi, K., et al. (2017). Current Status of Insecticide Resistance among Malaria Vectors in Kenya. Parasites and Vectors, 10(1), 429. doi:10.1186/s13071-017-2361-8, PubMed: 28927428.

Playfair, J.H.L., and Bancroft, G..J. (2008). Infection and Immunity (3rd ed). England Oxford; New York. Oxford University Press, xvi. ISBN: 9780199206735.

Pogo, A.O., and Chaudhuri, A. (1995). Duffy and Receptors for P. vivax and Chemotactic Peptides. Transfusion Clinique et Biologique: Journal de la Societe Francaise de Transfusion Sanguine, 2(4), 269-276. doi:10.1016/s12467820(05)80093-x, PubMed: 8542025.

Pogo, A.O., and Chaudhuri, A. (2000). The Duffy Protein: A Malarial and Chemokine Receptor. Seminars in Hematology, 37(2), 122-129. doi:10.1016/s0037-1963(00)90037-4, PubMed: 10791881.

Ravenhall, M., Campino, S., Sepúlveda, N. et al. (2018). Novel Genetic Polymorphisms Associated with Severe Malaria and Under Selective Pressure in North-Eastern Tanzania. PLOS Genetics, 14(1), e1007172. doi:10.1371/ journal.pgen.1007172. [PMCFree article]. PubMed: [CrossRef]. Google Scholar.

Reece, S.E., Prior, K.F., and Mideo, N. (2017). The Life and Times of Parasites: Rhythms in Strategies for Within-Host Survival and Between-Host Transmission. Journal of Biological Rhythms, 32(6), 516-533. doi:10.1177/ 0748730417718904, PubMed: 28845736.

Reimer, L.J., Thomsen, E.K., Koimbu, G., Keven, J.B., Mueller, I., Siba, P.M., et al. (2016). Malaria Transmission Dynamics Surrounding the First Nationwide Long-Lasting Insecticidal Net Distribution in Papua New Guinea. Malaria Journal, 15, 25. doi:10.1186/s12936-015-1067-7, PubMed: 26753618.

Riveron, J.M.M., Chiumia, M., Menze, B.D., Barnes, K.G., Irving, H., Ibrahim, S.S., et al. (2015). Rise of Multiple Insecticide Resistance in Anopheles Funestus in Malawi: A Major Concern for Malaria Vector Control. Malaria Journal, 14, 344. doi:10.1186/s12936-015-0877-y, PubMed: 26370361.

Roberts, D.J., and Williams, T.N. (2003). Haemoglobinopathies and Resistance to Malaria. Redox Report: Communications in Free Radical Research, 8(5), 304-310. doi:10.1179/135100003225002998, PubMed: 14962371.

Rowe, A., Obeiro, J., Newbold, C.I., and Marsh, K. (1995). Plasmodium falciparum Rosetting is Associated with Malaria Severity in Kenya. Infection and Immunity, 63(6), 2323-2326. doi:10.1128/IAI.63.6.2323-2326.1995, PubMed: 7768616.

Rowe, J.A., Claessens, A., Corrigan, R.A., and Arman, M. (2009). Adhesion of Plasmodium falciparum-Infected Erythrocytes to Human Cells: Molecular Mechanisms and Therapeutic Implications. Expert Reviews in Molecular Medicine, 11, e16. doi:10.1017/S1462399409001082, PubMed: 19467172.

Schneider, K.A., and Escalante, A.A. (2013). Fitness Components and Natural Selection: Why are there Different Patterns on the Emergence of Drug Resistance in Plasmodium falciparum and Plasmodium vivax? Malaria Journal, 12, 15. doi:10.1186/1475-2875-12-15, PubMed: 23305428. 
Shah, S.S.S., Rockett, K.A., Jallow, M., Sisay-Joof, F., Bojang, K.A., Pinder, M., et al. (2016). Heterogeneous Alleles Comprising G6PD Deficiency Trait in West Africa Exert Contrasting Effects on Two Major Clinical Presentations of Severe Malaria. Malaria Journal, 15, 13. doi:10.1186/s12936-015-1045-0, PubMed: 26738565.

Silva, A. P., Santos, J. M. and Martins, A.J. (2014). Mutations in the Voltage-Gated Sodium Channel Gene of Anophelines and their Association with Resistance to Pyrethroids_A Review. Parasites and Vectors, 7, 450. doi:10.1186/17563305-7-450, PubMed: 25292318.

Smith, C.M.M., Jerkovic, A., Puy, H., Winship, I., Deybach, J.C., Gouya, L., et al. (2015). Red Cells from FerrochelataseDeficient Erythropoietic Protoporphyria Patients are Resistant to Growth of Malarial Parasites. Blood, 125(3), 534541. doi:10.1182/blood-2014-04-567149, PubMed: 25414439.

Snow, R.W., Guerra, C.A., Noor, A. M., Myint, H.Y., and Hay, S.I. (2005). The Global Distribution of Clinical Episodes of Plasmodium falciparum malaria. Nature, 434(7030), 214-217. doi:10.1038/nature03342, PubMed: 15759000.

Trape, J.F., Pison, G., Preziosi, M.P., Enel, C., Desgrées du Loû, A., Delaunay, 690 V., et al. (1998). Impact of Chloroquine Resistance on Malaria Mortality. Comptes Rendus de l'Academie des Sciences. Serie III, Sciences de la Vie, 321(8), 689-697. doi:10.1016/s0764-4469(98)80009-7, PubMed: 9769862.

van Bruggen, R., Gualtieri, C., Iliescu, A., Louicharoen Cheepsunthorn, C., Mungkalasut, P., Trape, J. F., et al. (2015). Modulation of Malaria Phenotypes by Pyruvate Kinase (PKLR) Variants in a Thai Population. PLOS ONE, 10(12), e0144555. doi:10.1371/journal.pone.0144555, PubMed: 26658699.

Vincent, C., and N'Guessan, R. (Eds.). (2013). Mechanisms, Impact and Management of Insecticide Resistance in Malaria Vectors: A P Ragmatic. Intech Open.

von Kalckreuth, V., Evans, J.A., Timmann, C., Kuhn, D., Agbenyega, T., Horstmann, R.D., and May, J. (2006). Promoter Polymorphism of the Anion Exchange Protein 1 Associated with Severe Malarial Anemia and Fatality. Journal of Infectious Diseases, 194(7), 949-957. doi:10.1086/507430, PubMed: 16960783.

Wassmer, S.C.C. and Carlton, J.M. (2016). Glycophorins, Blood Groups, and Protection from Severe Malaria. Trends in Parasitology, 32(1), 5-7. doi:10.1016/j.pt.2015.11.006, PubMed: 26613665.

Weppelmann, T.A.A., Carter, T.E., Chen, Z., von Fricken, M.E., Victor, Y.S., Existe, A., and Okech, B.A. (2013). High Frequency of the Erythroid Silent Duffy Antigen Genotype and Lack of Plasmodium vivax Infections in Haiti. Malaria Journal, 12, 30. doi:10.1186/1475-2875-12-30, PubMed: 23347639.

Williams, T.N., Weatherall, D.J., and Newbold, C.I. (2002). The Membrane Char Acteristics of Plasmodium falciparumInfected and -Uninfected Heterozygous Alpha(0)thalassaemic Erythrocytes. British Journal of Haematology, 118(2), 663-670. doi:10.1046/j.1365-2141.2002.03610.x, PubMed: 12139762.

World Health Organization. (2008). World Malaria Report. Retrieved from http://apps.who.int/malaria/wmr2008/ malaria2008.pdf. Geneva, Switzerland: World Health Organization Press.

Yuthavong, Y., and Wilairat, P. (1993). Protection against Malaria by Thalassaemia and Haemoglobin Variants. Parasitology Today, 9(7), 241-245. doi:10.1016/0169-4758(93)90065-n, PubMed: 15463767.

Zimmerman, P.A., Woolley, I., Masinde, G.L., Miller, S.M., McNamara, D.T., Hazlett, F., et al. (1999). Emergence of FY*A(null) in a Plasmodium vivax Endemic Region of Papua New Guinea. Proceedings of the National Academy of Sciences of the United States of America, 96(24), 13973-13977. doi:10.1073/pnas.96.24.13973, PubMed: 10570183.

Zimmerman, R.H., Lounibos, L.P., Nishimura, N., Galardo, A.K., Galardo, C. D. and Arruda, M.E. (2013). Nightly Biting Cycles of Malaria Vectors in a Heterogeneous Transmission Area of Eastern Amazonian Brazil. Malaria Journal, 12, 262. doi:10.1186/1475-2875-12-262, PubMed: 23890413.

Cite this article as: Fatik Baran Mandal (2021). Survival Strategies of Host, Parasite, and Vector in Human Malaria. African Journal of Pharmaceutical Sciences, 1(1), 1-10. doi: 10.51483/AFJPS.1.1.2021.1-10. 